Max-Planck-Institut für demografische Forschung

Max Planck Institute for Demographic Research

Konrad-Zuse-Strasse 1 - D-18057 Rostock - GERMANY

Tel +49 (0) 3812081 - 0; Fax +49 (0) 3812081 - 202;

http://www.demogr.mpg.de

MPIDR WORKING PAPER WP 2015-004

SEPTEMBER 2015

\title{
Older parents benefit more in health outcome from daughters' than sons' care in China
}

Yi Zeng (zengyi68@gmal.com)

Melanie Sereny Brasher

Danan Gu

James W. Vaupel

(C) Copyright is held by the authors.

Working papers of the Max Planck Institute for Demographic Research receive only limited review. Views or opinions expressed in working papers are attributable to the authors and do not necessarily reflect those of the Institute. 


\title{
Older parents benefit more in health outcome from daughters' than sons' care in China ${ }^{1}$
}

\author{
Yi Zeng ${ }^{1,2} *$, Melanie Sereny Brasher ${ }^{3}$, Danan $\mathrm{Gu}^{4}$ and James W. Vaupel ${ }^{5}$
}

${ }^{1}$ Center for the Study of Aging and Human Development and Geriatric Division, Medical School of Duke University.

${ }^{2}$ Center for Healthy Aging and Development Studies, National School of Development, Peking University.

${ }^{3}$ Department of Sociology \& Anthropology, University of Rhode Island

${ }^{4}$ Population Division, Department of Economic and Social Affairs, United Nations, NY.

${ }^{5}$ Max Planck Institute for Demographic Research

* Please address correspondence to: Yi Zeng, Center for the Study of Aging and Human Development, Medical School of Duke University, and National School of Development, Peking University. Mailing address: Box 3003, Duke University, Durham, NC 27710, U.S.A. tel. 9196607554; fax: 919-668-0453; Email: zengyi68@gmal.com.

\section{ABSTRACT}

Objectives: To examine whether older parents in China would benefit more from daughters' care than from sons' care.

Methods: Analysis of the unique datasets of the Chinese Longitudinal Healthy Longevity Survey conducted in 2002, 2005 and 2008-2009 in 22 provinces.

Results: As compared to having son(s), having daughter(s) is significantly more beneficial at older ages in China, with regards to maintaining higher cognitive capacity and reducing mortality risk. Such daughter-advantages are more profound among the oldest-old aged 80+ as compared to the young-old aged 65-79, and surprisingly more profound in rural areas as compared to urban areas, even though son-preference is much more common among rural residents.

Discussion: We describe how educational campaigns aimed at informing the public about the benefits of daughter(s) for older parents' health outcome could help promote gender equality and reduce traditional son-preference, especially in rural China.

\footnotetext{
${ }^{1}$ The views expressed in this article are solely those of the authors and do not necessarily reflect those of Duke University, Peking University, the University of Rhode Island, the United Nations and the Max Planck Institute for Demographic Research. Dr. Danan Gu's work was mainly completed when he was at Duke University. He now works at the United Nations Population Division.
} 


\section{INTRODUCTION}

For thousands of years, both cultural tradition and economic benefits have led to the continued preference for sons in China, especial in rural areas. According to Confucian customs, only sons can perform ancestor worship and continue the family line (Ebenstein \& Leung, 2010), which is one of the main reasons why most people in rural China strongly prefer to have at least one son. The country's underdeveloped social welfare system for the elderly, particularly in rural areas, also contributes to son preference. The sentiment behind the old Chinese saying "Yang Er

Fang Lao" -- Having a son prevents difficulties in old ages -- is a belief held by many Chinese and a driving force behind son preference and discrimination against girls and women, especially in rural China.

Chinese culture is traditionally patriarchal, patrilineal, and patrilocal - adult sons are more likely to co-reside with their elderly parents and provide financial support, while daughters "marry out" and become members of their husband's family (Bian, Logan, \& Bian, 1998; Deutsch, 2006). Rural household labor supply also favors sons as they are better farm laborers and can also enhance family power in local conflicts (Ebenstein \& Leung, 2010). While daughters are less available to provide financial support to their own aged parents than sons, however, they can still provide instrumental and emotional care and support to natal parents. Such supports and their implications for older parents' health outcomes are rarely documented using large-scale nationwide surveys from China, and this paper aims to fill in this research gap. Based on data from three waves of the Chinese Longitudinal Healthy Longevity Survey (CLHLS), we explore whether and how elderly parents benefit from emotional support and caregiving by adult children, and how it may differ by the adult child's gender. In the remaining part of this introductory section, we will briefly review previous studies related to our research questions.

\section{Caregiving and emotional support to elderly parents from adult children}


Given the patriarchal nature of Chinese families, caregiving from sons generally means that the actual hands-on care to aged parents in need is provided by sons' wives - daughters-inlaw of elderly parents, while daughters usually marry out (Liu \& Kendig, 2000). In recent decades, the strengthening of the nuclear family (as opposed to the extended family), free-choice marriage and an increase in women's status may have led to stronger bonds between sons and their wives. Consequently, daughters-in-law are more involved with decision-making and have more power within the family, with husbands and wives negotiating elderly parents care arrangements in contemporary China (Zhang \& Wang, 2010). Such trends might increase conflicts in daily life between daughters-in-law and mothers-in-law, which are much more likely to occur, or even to be serious, as compared to daughter-mother relation, especially in rural areas (Meng, 2002; Pearson, 2002). As men are less likely to be caregivers than women, there is much lower potential for conflict between older parents and sons-in-law (Chappell \& Kusch, 2007).

The general perception that sons provide more care to older parents in the context of Chinese tradition contrasts with the Western cultural and social practices, which have been increasingly influencing Chinese society since the late 1970s when China openned its door to the world. In Western countries, daughters are more likely than sons to provide daily care to elderly parents (Raley \& Bianchi, 2006; Spitze \& Logan, 1990), particularly personal care and household tasks (Abel, 1990; Miller \& Cafasso, 1992). Some studies have shown that daughters (in other countries and China) are more likely to be actual caregivers than sons when the older parents are sick (Spitze \& Logan, 1990; Whyte, 2003).

Survey data from urban China have found that sons are more likely to provide financial support to their older parents, while daughters more likely to provide gifts and assistance in daily living to their older parents (Cooney \& Di, 1999; Sun, 2002; Zhan, 2004). In a study of entry into long-term care in Shanghai, daughters' availability to provide care mattered more than sons, a departure from traditional filial piety that a son should be the main caregiver (Chen \& Ye, 2013). In urban China, patrilocality may be declining, with the importance of sons (for old-age care) 
diminishing. Urban parents may be more willing to receive support from daughters, but reliance on sons (and daughters-in-law) persists in rural areas, where daughters' care is voluntary, and they are publically perceived as a "back-up" option if no sons are available (Zhang \& Wang, 2010). Xie \& Zhu (2009) found that only daughters who likely co-reside with elderly parents (going against traditional living arrangements), especially in rural China, have characteristics of emotional closeness with parents. One recent study finds that the oldest-old in urban China who were disabled in activities of daily living were 35-37\% more likely to report an unmet need of help, if the primary caregiver are sons/daughters-in-law, compared to urban oldest-old whose primary caregiver is daughters/sons-in-law (Zhu, 2015). Yet many studies under-recognize the role of daughters in caring for impaired older parents (Zhan, 2004).

Although there are fewer studies of emotional support (as opposed to financial support), evidence from the US found that daughters provide more emotional support than sons to both fathers and mothers (Chesley \& Poppie, 2009). Research from the Netherlands found that daughters have greater emotional support to elderly mothers than do sons when the mothers experience a health decline (Broese Van Groenou \& Knipscheer, 1999). Research found that emotional support was stronger from daughters than from sons in Hong Kong ( $\mathrm{Ng}$, Phillips, \& Lee, 2002) and in rural Mainland China (Cong \& Silverstein, 2012). This is consistent with the idea that daughters are kin-keepers of the family and more responsive to the needs of their older parents (Rossi \& Rossi, 1990; Li \& Seltzer, 2005). Research from rural northern China also provides evidence of elderly parents' happier relationships with daughters than with sons (Zhang \& Wang, 2010). A recent study, based on 4,479 older parent - adult child dyads interviewed in 2002 in China as part of the CLHLS, provided strong evidence that, controlling for various confounders of both adult children and elderly parents, adult daughters' filial piety index is significantly higher than that of sons; additionally, adult daughters' emotional relationships with older parents are significantly better than that of sons (Zeng et al., 2015). 


\section{Association between support from adult children (sons vs. daughters) and older parents' health outcomes}

A large literature demonstrates the importance of children's support for elderly parents' well-being (Silverstein \& Bengtson, 1994; Zunzunegui et al., 2001). In general, support from adult children has protective effects for elderly parent's health and mortality. In a Spanish study, older parents who received emotional support from children were more likely to have good self-rated health (Zunzunegui et al., 2001). Several studies from diverse populations (Europe, United States, Mainland China and Taiwan) have found that support from children reduces older parents' depressive symptoms (Buber \& Engelhardt, 2008; Byers et al., 2008; Li et al., 2005). A study from Taiwan found that older adults with activity limitations who shared their worries with adult children had fewer depressive symptoms (Weinstein et al., 2004). A U.S.-based study found that parents had reduced mortality risk when they had more affectionate relationships with adult children (Silverstein \& Bengtson, 1991).

Previous research demonstrated that the amount and type of support from children may vary by adult child's sex and cultural context (Silverstein \& Bengtson, 1994; Zunzunegui et al., 2001). In recent years, a number of studies have examined associations of sex composition of children and older parent's mortality and health (Cesarini, Lindqvist, \& Wallace, 2009; Hurt, Ronsmans \& Quigley, 2006). One recent study found no protective effect of sons on elderly parents' survival in either Mainland China or Taiwan, and it also found that, in Taiwan, daughters may have been more beneficial than sons in reducing older parents' mortality in recent years (Pham-Kanter \& Goldman, 2011). Similarly, research from rural Poland found that a higher number of daughters increased fathers' lifespan. This same study found that greater numbers of children (of either sex) reduce maternal longevity (Jasienska, Nenko \& Jasienski, 2006). A study from rural Bangladesh found no effect of number of daughters on either maternal or paternal mortality, but greater number of sons increased mortality for parents (Hurt, Ronsmans \& Quigley, 2006). 


\section{Hypotheses to be tested}

Based on the literature reviewed above and the relevant unique data we have in hand, we intend to empirically test the following hypothesis:

H1: Older parents' health outcomes may benefit more from care provided by daughters (and sons-in-law) than that provided by sons (and daughters-in-law).

To test this hypothesis, we will explore how caregiving received from adult daughters (and sons-in-law) versus sons (and daughters-in-law) and gender composition of children may be associated with older parents' health indicators and mortality risk.

The oldest-old most likely need care and have been growing at a much faster rate than the young-old, and the rural-urban gap of old-age care is dramatically large in China (Zeng \& George, 2010). Yet, no previous studies have compared the oldest-old and young-old parents, or differences in rural and urban residents, with respect to how sex composition of children and care from daughters versus sons affects older parents' health outcomes. We will try to fill in this research gap in this article. In addition, based on presentation and discussion of the results of the empirical analysis, we will discuss related policy recommendations.

\section{DATA SOURCE, MEASURES AND METHODS}

\section{Data source}

The data used in this article are from the third, fourth and fifth waves of the Chinese Longitudinal Healthy Longevity Survey (CLHLS), conducted in 2002, 2005 and 2008-2009, with a total sample size of 19,697 respondents aged 65+ from these three waves of CLHLS (see Table 1 for more details). The CLHLS baseline survey was conducted in 1998, and all of its follow-up surveys include re-interviews to survival participants. In the first four follow-up surveys conducted in 2000, 2002, 2005 and 2008-2009, CLHLS also included replacement for deceased and lost-to- 
follow-up elders. The CLHLS has been conducted in randomly selected about half of the counties and cities in 22 of the 31 provinces and municipalities of China (Liaoning, Jilin, Heilongjiang, Hebei, Beijing, Tianjin, Shanxi, Shaanxi, Shanghai, Jiangsu, Zhejiang, Anhui, Fujian, Jiangxi, Shandong, Henan, Hubei, Hunan, Guangdong, Guangxi, Sichuan, and Chongqing) ${ }^{1}$. The survey areas covered 985 million persons in the 1998 baseline year, which was about 85 percent of the total population of China. The 1998 baseline and 2000 follow-up surveys included oldest-old interviewees aged 80+ and did not include younger elders aged 65-79. The CLHLS survey has been expanded in the 2002 and later waves to cover ages 65 and above through the addition of a new sub-sample of interviewees aged 65-79. The CLHLS adopted a targeted random-sample design to insure the representativeness, even distribution and large enough sub-sample size of the oldest-old aged 80-110, with appropriately compatible young-old aged 65-79. More specifically, the CLHLS baseline survey tried to interview all centenarians who voluntarily agreed to participate in the study in the sampled counties and cities; for each centenarian interviewee, the CLHLS interviewed one randomly selected nearby octogenarian and one randomly selected nearby nonagenarian of predefined age and sex. In the 2002, 2005, and 2008-2009 waves, the CLHLS interviewed approximately three randomly selected nearby elders aged 65-79 of predefined age and sex in conjunction with every two centenarians. The face-to-face questionnaire data were collected in the CLHLS using internationally standardized questionnaires adapted to the Chinese cultural and social context. Information about the date of death and health status of the elderly who were interviewed in the previous wave but died before the subsequent survey was collected by interviewing a close family member (Zeng \& Gu, 2008).

The systematic assessments on data quality concerning accuracy of age-reporting, reliability, validity, consistency of the main measures, and randomness of attrition show reasonably good quality in the CLHLS data sets (Goodkind, 2009; Gu \& Dupre, 2008; Zeng, 2012). The unique CLHLS datasets have been publicly available and widely applied in healthy 
aging studies by scholars around the world. For more information of the technical documents and the list of publications using the CLHLS datasets, refer to: www.geri.duke.edu/china.

\section{Measures}

The dataset used in this study include 19,696 older parents who were interviewed in 2002 or 2005 and their follow-up data collected in 2005 or 2008-2009 (see Table 1 for age and rural/urban sample compositions).

Dependent variables:

(1) Changes in cognitive function of older parents. The cognitive function of the elderly interviewees in the CLHLS was screened by the Chinese version of the Mini-Mental State Examination (MMSE), which has the same contents as the international standard of the MMSE questionnaire (Folstein, Folstein, \& McHugh, 1975), but the CLHLS team culturally translated and adapted it into the Chinese language. The CLHLS team did careful pilot interview tests to validate the Chinese version of MMSE before the surveys were conducted. The total possible score on the MMSE is 30 , with lower scores indicating poorer cognitive ability. We defined those who had a score of less than 24 as cognitively impaired as suggested by Folstein et al. (1975) and widely used internationally and in the Chinese studies. Previous publications concerning cognitive function using the CLHLS data confirmed that such a cutoff is valid (Shen \& Zeng, 2010; Yin et al., 2012). Cognitive capacity decline was defined as when a person whose score was greater than 24 in 2002 or 2005 but had a score less than 24 in 2005 or 2008-2009.

(2) Activities of daily living ( $A D L)$. If an older parent needed help to perform any of the six daily tasks of bathing, dressing, indoor transferring, toileting, eating, and incontinence, he/she was considered ADL disabled and needed daily care; otherwise, he/she was not disabled and did not need daily care. 
(3) Self-rated health. The CLHLS asked the question "How do you rate your health at present?" to each interviewee and no proxy answers are allowed. The possible answers to this question were grouped into two categories of "Good" and "Not good".

(4) The deficits index (DI; previously called the frailty index), which has been widely applied in healthy aging studies, is a summation of deficits in variables reflecting different dimensions of health conditions. Following the general international practice (Kulminski et al., 2008; Goggins et al., 2005), we estimated the DI for each respondent from 39 variables, with a score of 1 if the condition was present, and a score of 2 if a serious illness caused the person to be bedridden or hospitalized. These variables included cognitive function, ADL, instrumental ADL, physical performance, self-rated health, interviewer-reported health, hearing and vision loss, heart rhythm, psychological distress, serious illness in the past 2 years, and specific chronic diseases. We then constructed a DI by summarizing all deficits and dividing by the total number of possible deficits. We treat DI scores as a continuous variable.

(5) Mortality risk. As described in the "Data Source" Section above, information on date of death were collected for the interviewees who were interviewed in 2002 or 2005, but died in the interwave period $2002-2005$ or $2005-2008 / 2009$. Survival time was entered as days counted from the date of the interview in 2002 or 2005 to the date of the interview in 2005 or 2008-2009 for survivors and to the date at death for the deceased, while we controlled for respondent's initial age in 2002 or 2005.

The key independent variables of interests: the gender composition of surviving children (having daughter(s) only versus having son(s) only; and having daughter(s) only versus having both son(s) and daughter(s)), as well as with whom (daughter and son-in-law versus son and daughter-in-law) the parent shares feelings most frequently.

The variable "with whom the parent shares feelings most frequently" is based on the question "To whom do you talk first when you need to share something of your thoughts?" The 
possible answers (choose one) are: spouse; son; daughter; daughter-in-law; son-in-law; grandchildren and their spouses; other relatives; friends/neighbors; social workers; housekeeper; nobody. Those who answered daughter or son-in-law were combined into one category, and those who answered son or daughter-in-law were combined into one category. This is because daughter and son-in-law are a married couple and son and daughter-in-law are a married couple, and a married couple shares the familial responsibility, financial interests and decision-making. We do so also to avoid unnecessary complication with too many categories. We focus on comparing the odds ratios of daughter and son-in-law versus son and daughter-in-law in this article. In Chinese society, elderly parents usually talk first with the adult child to whom the older parent trusts most and has the best emotional relations with when the parents need to share something of his or her thoughts. Therefore, we regard "sharing feeling with daughter/son-in-law or son/daughter-in-law most frequently" as one of the indicators of a good emotional relationship between older parents and adult children.

Potentially confounding variables: the elderly respondents' gender, single year of age, urban/rural residence (defined by the respondents' actual long-term residential locations rather than the strict Chinese household registration (hukou) system), number of living children, proximity to children, ethnicity, education, economic status, marital status, and health practices at their interviews in 2002 or 2005 . For the survival analysis using mortality risk as the dependent variable, we also controlled for respondents' health status measured by the Deficit Index at their interviews in 2002 or 2005.

The frequency distributions of the sample by the dependent variables, key independent variables and the potentially confounding variables are listed in Table 1.

--Table 1 about here---

\section{Statistical Methods}


In seeking answers to our research questions based on the datasets from the CLHLS 2002, 2005 and 2008-2009 waves, the statistical methods of logistic regression and parametric Weibull hazards survival analysis were employed. More specifically, we used binary logistic regression models to predict follow-up declining capacities in cognitive function, ADL disability, and self-rated health, with key independent variables of gender composition of surviving children and sharing feelings with daughter (and son-in-law) versus son (and daughter-in-law), controlling for other potential confounding variables. We used binary and ordered logistic regressions as well as linear regressions to explore the effects of gender composition of surviving children and sharing feeling with children on older parents' deficit index, adjusting for other potential confounding variables. Because the proportionality assumption in Cox proportional hazards regressions was violated in some covariates (e.g., education and economic status) and Weibull survival analysis yielded the lowest Akaike Information Criterion (AIC) index than other parametric survival regressions, we use Weibull hazards survival analysis model to address how gender composition of living children and sharing feelings most frequently with daughter (and son-in-law) versus son (and daughter-in-law) may affect older parents' subsequent mortality. Following a similar strategy adopted in other studies (Crimmins, Hayward \& Saito, 1994), those first interviewed in 2002 or 2005 as well as their follow-up data are pooled in the present study to increase statistical precision and produce more robust results. Note that each person has only one observation in the analysis and thus there are no intrapersonal cluster effects. We tried the analysis controlling for survey wave and it did not substantively change the results, as the 2002 and 2005 waves were close each other and thus there is no need to include survey wave as a covariate. As the proportion of missing value of each of the variables in this study is less than $2 \%$, we imputed them with the mode if the variables are categorical or binary and with the means if they are continuous. Other alternative strategies were also tried and the results were almost identical. 


\section{RESULTS}

The daughter-advantage may help older parents to have a lower risk of follow-up decline in cognitive capacity

Table 2 presents the estimates of the odds ratios of follow-up decline in cognitive capacity comparing those elderly who most frequently share feelings with a daughter (and son-in-law) in daily life versus those who most frequently share feelings with a son (and daughter-in-law), as well as comparing the parents with different gender composition of surviving children. The estimates in panel (A) of Table 2 show that, as compared to those elderly who most frequently talk to a son (and daughter-in-law) in daily life, the elderly aged 65+ who most frequently talk to a daughter (and son-in-law) had significantly lower risk $(P<0.05 ;$ OR $=0.84$ ) of declining cognitive capacity in the 3-year period. Such daughter-advantage in preventing decline in cognitive capacity at older ages is much stronger in rural areas $(p<0.05$; OR $=0.68)$ than in urban areas (not statistically significant; OR =1.0). The estimates of odds ratios indicate that the risk of follow-up decline in cognitive capacity of older parents who have daughter(s) only was smaller than those who have sons only (see panel (B) of Table 2), and smaller than those who have both sons and daughters (see panel (C) of Table 2). However, none of these estimates are statistically significant.

--- Table 2 is about here---

\section{Results of the regressions using ADL, self-rated health and deficit index as dependent variables}

While our empirical analysis has demonstrated that the daughter-advantage significantly helped older parents to have a lower risk of follow-up decline in cognitive capacity, additional analysis (data not presented here but available upon request) indicated that gender composition 
of children had no statistically significant association with older parents' subsequent decline in functional capacity of activities of daily living (ADL), self-rated health and deficit index. These results indicate that the benefit of having daughter(s) for the elderly parents may be more evident with respect to mental health, which is closely related to emotional care, rather than physical health and subjective well-being, which often demands good financial support. It has been shown that financial support could help to provide necessary facilities and a favorable living environment so that ADL disability and poor self-rated health of elders could be avoided even in the presence of a decline in physical health (Feng et al., 2010; Purser et al., 2012; Feng, Son, \& Zeng, 2015). It is thus understandable that having daughter(s) did not result in significant benefits for older parents in their ADL capacity, subjective well-being and deficit index, because, as compared to son(s), Chinese daughter(s) are not as advantageous in providing financial support to their elderly parents.

\section{Daughter-advantage may help older parents to have lower mortality risks}

Table 3 presents the estimates of the relative risk of mortality comparing elderly parents who shared feelings most frequently with a daughter (and son-in-law) versus a son (and daughter-in-law), and also associations with the gender composition of their living children. Statistically significant reduction in the relative risk of mortality are found for those elderly aged $65+$ (rural and urban combined) who shared feelings most frequently with daughter (and son-inlaw) $(p<0.05 ;$ OR $=0.93$; panel I-(A) of Table 3$)$, as compared with the older parents who shared feelings most frequently with son (and daughter-in-law). This effect is statistically significant among the oldest-old parents of rural-urban combined $(p<0.01, \mathrm{OR}=0.92$; panel III-(A) of Table 3), but there is no significant effect among young-old parents of rural-urban combined (panel II(A) of Table 3).

As compared with those who shared feelings most frequently with a son (and daughter-inlaw), those who share feelings most frequently with a daughter (and son-in-law) had significantly 
lower mortality risk among the rural oldest-old aged $80+(p<0.01 ;$ OR $=0.86$; III-(A) of Table 3$)$ and for all rural elders aged $65+(p<0.01 ;$ OR $=0.87$; I-(A) of Table 3$)$, respectively, but there was no statistically significant effect among urban oldest-old and all elderly parents (panels III-(A) and I-(A) of Table 3).

As compared to those female elderly aged $65+$ who have son(s) only, those elderly mothers 65+ with daughter(s) only had significantly lower mortality risk in the follow-up periods $(\mathrm{P}<0.01 ; \mathrm{OR}=0.90 ; \mathrm{I}-(\mathrm{B})$ of Table3). However, the corresponding estimates for male elderly are not statistically significant $(\mathrm{I}-(\mathrm{B})$ of Table 3$)$. It is very interesting to note that the mortality reduction associated with having daughter(s) only (vs. having son(s) only) is substantial and statistically significant among oldest-old mothers $(p<0.01$, OR $=0.90$, III-(B) of Table 3 ), but

there are no significant effects for young-old mothers (II-(B) of Table 3). As shown in panels I-(C), II-(C) and III-(C) of Table 3, elderly (either young-old or oldest-old) who have daughter(s) only and elderly who have both son(s) and daughter(s) do not demonstrate any statistically significant differences in the estimates of the relative risk of mortality.

--- Tables 3 is about here---

\section{DISCUSSION}

Based on a unique and large dataset, our analysis clearly demonstrates that, as compared to having son(s), having daughter(s) is beneficial for older parents in China, with respect to maintaining a better cognitive capacity and reducing mortality risk, while controlling for various confounding factors. Our analysis has provided strong empirical evidence to support the hypotheses based on our review of the relevant literature outlined in the introduction of this paper. We discovered that such daughter-advantages are generally more profound among the oldest-old parents as compared to young-old parents, and surprisingly more profound in rural areas as compared to urban areas $^{2}$, even though son-preference is much more prevalent among rural residents. 
How to explain these findings, which contradict the commonly held son preference in China, especially in rural areas? We believe that it may be at least partly explained by gender differences in adult children's roles in emotional support for older parents and changes in these roles in recent years. Although adult sons usually provide more financial support to their older parents in China, especially in rural areas, adult daughters who are more filial than adult sons (Zeng et al., 2015) are likely provide better emotional care to their elderly parents who frequently need it, as shown here and in other studies (Chesley \& Poppie, 2009; Cong \& Silverstein, 2012; Spitze \& Logan, 1990; Sun, 2002; Whyte, 2003; Zhu, 2015). For example, as compared to adult sons who are usually busy and may not like to talk with their older parents in depth, adult daughters who have better emotional relationship with elderly parents (Zeng et al., 2015) may listen more carefully and patiently. In addition, they are more likely to respond to what older parents say and to provide emotional and daily care to parents if they need help (Broese Van Groenou \& Knipscheer, 1999; Spitze \& Logan, 1990). In contrast, the tension between daughtersin-law and mothers-in-law is the most frequent dispute in intergenerational relationships in China (Yang \& Chhandler, 1992). Based on data from the 2005 and 2008-2009 waves of CLHLS, a recent study found that ADL (activity of daily living) disabled elderly aged 65+ whose primary care-providers are a daughter (and son-in-law) are significantly more likely to be satisfied with care received than their counterparts whose primary care-providers are a son (and daughter-inlaw), and the corresponding estimates are highly significant among oldest-old parents $80+$, but not significant among younger parents aged 65-79 (Zeng et al., 2015). Clearly, it is interpretable that our empirical analyses demonstrating older parents who share feelings most frequently with daughters (and sons-in-law), compared to sons (and daughters-in-law), have significantly lower risk of cognitive capacity decline and lower mortality risk (Tables 2 and 3).

Given the fact that pension supports are generally underdeveloped, especially in rural areas, those who have no sons are very likely to live with a married daughter and they may be better-off in receiving daily care compared to those who have son(s) only and may face the 
challenge of conflict between daughter-in-law and mother-in-law. These factors may lead to the elderly who have daughter(s) only being substantially better-off in terms of cognitive capacity and survival probability, compared to those who have son(s) only (Tables 2 and 3). Or, at a minimum, not being worse off because of a lack of male children.

We found that, comparing the elderly who have daughter(s) only with those elderly who have both son(s) and daughter(s), there is no statistically significant difference in all of the estimates of older parents' follow-up cognitive capacity decline and the relative risk of mortality (panel (C) of Table 2 and panels I-(C), II-(C) and III-(C) of Table 3). This is consistent with findings from the study by Pham-Kanter and Goldman (2011) using data from Mainland China and Taiwan (as reviewed earlier). Furthermore, another study using the CLHLS data demonstrated that daughters (and son-in-laws) provided more satisfactory care to their disabled older parents than sons (and daughter-in-laws) did, even when both sons and daughters are available in the family (Zeng et al., 2015). One possible explanation for our and others' findings is that the conflicts in daily life between daughter-in-law and mother-in-law are much more likely to occur, or even to be serious, as compared to daughter-mother relations (Meng, 2002; Pearson, 2002). The potential risk of conflict and poorer relationships between daughter-in-law and mother-in-law in China may counteract the effects of extra resources for those older parents who have both son(s) and daughter(s).

Compared to urban areas, the conflicts between daughters-in-law and mothers-in-law may be more likely to occur in rural areas today where the sons are more likely to be absent due to rural-to-urban labor migration, which has increased dramatically in recent years. Furthermore, the more complicated household work in rural areas may result in more frequent direct interactions and higher likelihood of conflict in daily life between co-residing daughters-in-law and mothers-in-law than that in urban areas. The generally lower education level of rural daughters-in-laws and mothers-in-laws may also result in poorer capability of resolving their daily life conflicts as compared to their urban counterparts. Previous studies found that the 
tension between daughters-in-law and mothers-in-law is the most frequent dispute in intergenerational relationships in rural China (Yang \& Chandler, 1992).

After more than thirty years of rapid economic and social development, rural daughters and their husbands can acquire more education, technical skills and economic capacity, which may reduce their disadvantages in familial affairs and power, and reduce the gap between daughters and sons (Xu, 2001). Therefore, although peasants' pre-dominant perception of sonpreference persists, the traditional advantages of sons may be relatively weaker today. Thus, it is interpretable that daughter-advantages are more profound in rural areas as compared to urban areas, although son-preference is still much more prevalent among rural residents, mainly because of Chinese cultural traditions and underdevelopment of the pension system in rural areas.

The oldest-old are more frail and vulnerable in cognitive capacity decline and mortality risk as age advances, and thus daughters' better and more careful emotional care would be more beneficial and effective for the oldest-old parents than for the young-old parents. Another possible explanation is that the children of the oldest-old - who are elderly themselves or at least middleaged - may have higher filial piety than adult children of the young-old, due to more connections to and influence from traditional Chinese family values of the period that they grew up in. This may enable the oldest-old to receive and benefit more and better emotional support from older children than the young-old receive from relatively younger children.

Clearly, our empirical findings that older parents may benefit more in cognition and survival from daughters' emotional support than from sons in China, especially in rural areas and among the oldest-old, are plausible and explainable by the Chinese social context and reality today. But such facts may still be covered up or diluted by the strong traditional son-preference. Thus, we recommend that the Chinese government and society may add daughters' advantages in providing better and more effective emotional care to elderly parents into existing educational propaganda programs (such as media reports, movies, and TVs shows) aimed to reduce gender 
disparities. Such actions may be helpful in efforts of reducing the traditional idea of "Yang Er Fang Lao" (Having a son prevents difficulties in old age) which is one core idea behind son preference, especially in rural areas. This is particularly relevant today, because emotional support may become more important than financial support in China where the living conditions of a large majority of the population, including the elderly, has been substantially improved. The public media propaganda on daughter's advantage in providing care to older parents based on data from a nationwide large longitudinal survey may be particularly informative for young couples who do not currently face the challenges of care needs and may not anticipate being disabled in their old ages. However, these empirical findings and policy recommendations are far from sufficient to eliminate the traditional son preference, because other important factors are operating and must be taken into consideration.

As mentioned in the introduction, one of the major problems behind the persistence of son preference in China is the underdevelopment of the pension system in rural China, where the elderly rely heavily on monetary transfers and other kinds of economic support from adult children, mainly sons (Chu, Xie, \& Yu, 2001). In contrast, the elderly in urban areas in China (and more developed countries) get most of their financial support from pensions and savings. The most recent development in rural old age insurance was that in September 2009, the Chinese State Council officially announced to launch and develop the nationwide "New Rural Pension Program (NRPP)" (Ye, 2009). Since then, the NRPP has been developed rapidly. According to Hu, Yang and Yan (2015), the number of participants in NRPP reached 460 million by the end of 2012, which represents nearly full coverage of participation in rural China. As compared to the previous rural old age insurance program which had very limited coverage and governmental funding, the new national NRPP has considerably more government subsidy and back-up funds. In the new program, it is explicitly stated that the premium is jointly paid by individuals, local and central governments, and the governments will ensure a basic and minimum income level for all elderly who participate in the program. With this most recent and promising policy guidance, actions are 
being taken and the New Rural Pension Program is expected to be quickly developed. Its effectiveness, however, remains to be seen and more action is necessary to increase its efficiency and to effectively implement the pension program in poorer rural areas.

In sum, we firmly believe that China needs to strengthen the integrative policy-related actions: (1) effectively inform the public that daughters' better care to older parents is beneficial for some important aspects of parents' health, including maintaining higher cognitive capacity and reducing mortality risk, especially in rural areas and at oldest-old ages; (2) further develop the pension system to fully cover all rural and urban residents; (3) continuously and effectively promote equality between males and females. We expect that strengthening these integrated policy-related actions would substantially reduce and eventually eliminate traditional son preference and enable Chinese elderly to enjoy a better life.

\section{REFERENCES}

Abel, E. K. (1990). Informal care for the disabled elderly. Research on Aging, 12(2), 139.

Bian, F., Logan, J. R., \& Bian, Y. (1998). Intergenerational relations in urban China: Proximity, contact, and help to parents. Demography, 35(1), 115-124.

Broese Van Groenou, M. I., \& Knipscheer, C. P. (1999). Onset of physical impairment of independently living older adults and the support received from sons and daughters in the Netherlands. The International Journal of Aging and Human Development, 48(4), 263-278.

Buber, I., \& Engelhardt, H. (2008). Children's impact on the mental health of their older mothers and fathers: findings from the Survey of Health, Ageing and Retirement in Europe. European Journal of Ageing, 5(1), 31-45. doi: 10.1007/s10433-008-0074-8

Byers, A. L., Levy, B. R., Allore, H. G., Bruce, M. L., \& Kasl, S. V. (2008). When Parents Matter to Their Adult Children: Filial Reliance Associated With Parents' Depressive Symptoms. The Journals of Gerontology Series B: Psychological Sciences and Social Sciences, 63(1), P33-P40.

Cesarini, D., Lindqvist, E., \& Wallace, B. (2009). Is there an adverse effect of sons on maternal longevity? Proceedings of the Royal Society B: Biological Sciences, 276(1664), 20812084.

Chappell, N. L., \& Kusch, K. (2007). The gendered nature of filial piety-a study among Chinese Canadians. Journal of Cross-Cultural Gerontology, 22(1), 29-45.

Chen, L. \& Ye M. (2013). The role of children's support in elders' decisions to live in a Yanglaoyuan (Residential Long-Term Care). Journal of Cross-Cultural Gerontology, 28(1):75-87.

Chesley, N., \& Poppie, K. (2009). Assisting Parents and In-Laws: Gender, Type of Assistance, and Couples' Employment. Journal of Marriage and Family, 71(2), 247-262. 
Chu, C., Xie, Y., \& Yu, R. R. (2011). Coresidence with elderly parents: A comparative study of Southeast China and Taiwan. Journal of Marriage and Family, 73(1), 120-135.

Coale, A.J. \& Li, S. (1991). The effect of age misreporting in China on the calculation of mortality rates at very high ages. Demography $28,293-301$.

Cong, Z., \& Silverstein, M. (2012). Caring for grandchildren and intergenerational support in rural China: a gendered extended family perspective. Ageing and Society, 32(3), 425.

Cooney, R. S., \& Di, J. (1999). Primary family caregivers of impaired elderly in Shanghai-China: kin relationship and caregiver burden. Research on Aging, 21(6), 739-761.

Crimmins, E.M. Hayward, M.D. \& Saito Y. (1994). Changing mortality and mobility rates and health status and life expectancy of older population. Demography, 31 (1).

Deutsch, F. M. (2006). Filial piety, patrilineality, and China's One-child policy. Journal of Family Issues, 27(3), 366.

Ebenstein, A., \& Leung, S. (2010). Son Preference and Access to Social Insurance: Evidence from China's Rural Pension Program. Population and Development Review, 36(1), 47-70.

Feng, Q., Hoenig, H.M., Gu,D., Zeng, Y., \& Purser, J.L. (2010). Impact of new disability subtypes on 3-year mortality in Chinese older adults. Journal of the American Geriatrics Society, 58(10), 1952-1958.

Feng, Q., Son, J., \&\& Zeng, Y. (2015). Prevalence and correlatesc of successful ageing: A comparisonc between China and South Korea. European Journal of Ageing, 12(2), 83-94.

Folstein, M. F., Folstein, S. E., \& McHugh, P. R. (1975). " Mini-mental state". A practical method for grading the cognitive state of patients for the clinician. Journal of Psychiatric Research, 12(3), 189-198.

Goodkind, D. (2009). Review of the book Healthy Longevity in China: Demographic, Socioeconomic, and Psychological Dimensions. Population Studies, 63(3), 1-7.

Goggins WB, Woo J, Sham A, Ho SC. Frailty index as a measure of biological age in a Chinese population. J Gerontol A Biol Sci Med Sci. 2005;60(8):1046-1051.

Gu, D., \& Dupre, M. E. (2008). Assessment of reliability of mortality and morbidity in the 19982002 CLHLS waves. In Y. Zeng, D. Poston, D. A. Vlosky \& D. Gu (Eds.), Healthy Longevity in China: Demographic, Socioeconomic, and Psychological Dimensions (pp. 99116). Dordrecht: Springer.

Hu, A., Yang, Z., \& Yan, Y. (2015). Trends and tasks of social security in China in the 13th fiiveyear national development plan period. Journal of the Party School of the Central Committee of the C.P.C, 1, 85-90. [in Chinese]

Hurt, L., Ronsmans, C., \& Quigley, M. (2006). Does the number of sons born affect long-term mortality of parents? A cohort study in rural Bangladesh. Proceedings of the Royal Society B: Biological Sciences, 273(1583), 149-155.

Jasienska, G., Nenko, I., \& Jasienski, M. (2006). Daughters increase longevity of fathers, but daughters and sons equally reduce longevity of mothers. American Journal of Human Biology, 18(3), 422-425.

Kulminski AM, Ukraintseva SV, Kulminskaya IV, Arbeev KG, Land KC, Yashin AY. Cumulative deficits better characterize susceptibility to death in the elderly than phenotypic frailty: lessons from the Cardiovascular Health Study. J Am Geriatr Soc. 2008;56(5):898-903.

Li, L. W., \& Seltzer, M.M., (2005). Relationship quality with parent, daughter role salience, and self-esteem of daughter caregivers. Marriage \& Family Review, 37(1-2), 63-82.

Li, L., Liang J., Toler A. and Gu S. (2005). "Widowhood and depressive symptoms among older Chinese: do gender and source of support make a difference?" Social Science \& Medicine 60(3):637-647. doi: 10.1016/j.socscimed.2004.06.014.

Liu, W. T., \& Kendig, H. (2000). Critical issues of caregiving: East-West dialogue. Who should Care for the Elderly, 1-23.

Meng, L. (2002). Rebellion and revenge: the meaning of suicide of women in rural China. International Journal of Social Welfare, 11(4), 300-309. doi: 10.1111/1468-2397.00239 
Miller, B., \& Cafasso, L. (1992). Gender differences in caregiving: fact or artifact? The Gerontologist, 32(4), 498.

Ng, A. C. Y., Phillips, D. R., \& Lee, W.K. (2002). Persistence and challenges to filial piety and informal support of older persons in a modern Chinese society: A sase study in Tuen Mun, Hong Kong. Journal of Aging Studies, 16(2), 135-153.

Pearson, V. (2002). Ling's death: An ethnography of a Chinese woman's suicide. Suicide and Life-Threatening Behavior, 32(4), 347-358.

Pham-Kanter, G., \& Goldman, N. (2011). Do sons reduce parental mortality? Journal of Epidemiology and Community Health, 66 (710-715).

Poston, D.L.,Jr., \& Luo H. (2004). Zhongguo 2000 nian shaoshu minzu de nian ling dui ji he shu zi pian hao (Age structure and composition of the Chinese minorities in 2000). Zhongguo Shaoshu Minzu Renkou (Chinese Minority Populations) 19 (3), pp. 9-15.

Purser, J.. L., Golightly, Y., Feng, Q., Helmick, C., Renner, J., \&\& Jordan, J. (2012). Slower walking wsaiko related outcomes.o Arthritis Care \& Research, 64(7), 1028-1035.

Raley, S., \& Bianchi, S. (2006). Sons, daughters, and family processes: Does gender of children matter? Annual Review of Sociology, 32, 401-421.

Rossi, A. S., \& Rossi, P. H. (1990). Of human bonding: Parent-child relations across the life course: Aldine.

Shen, K., \& Zeng, Y. (2010). The association between resilience and survival among Chinese elderly. Demographic research, 23(5), 105.

Silverstein, M., \& Bengtson, V. L. (1991). Do close parent-child relations reduce the mortality risk of older parents? Journal of Health and Social Behavior, 382-395.

Silverstein, M., \& Bengtson, V. L. (1994). Does intergenerational social support influence the psychological well-being of older parents? The contingencies of declining health and widowhood. Social Science \& Medicine, 38(7), 943-957.

Spitze, G., \& Logan, J. (1990). Sons, daughters, and intergenerational social support. Journal of Marriage and Family, 52(2), 420-430.

Sun, R. (2002). Old age support in contemporary urban China from both parents' and children's perspectives. Research on Aging, 24(3), 337-359.

Wang, Z., Zeng, Y., Jeune, B., and Vaupel J.W. (1998). Age validation of Han Chinese centenarians. GENUS 54, 123-141.

Weinstein, M., Glei, D.A., Yamazaki, A., \& Chang, M-C. (2004). The role of intergenerational relations in the association between life stressors and depressive symptoms. Research on Aging, 26(5), 511-530. doi: 10.1177/0164027504266463.

Whyte, M. K. (Ed.). (2003). China's Revolutions and Intergenerational Relations. Ann Arbor: The University of Michigan Press.

Xie, Y., \& Zhu, H. (2009). Do sons or daughters give more money to parents in urban China? Journal of Marriage and Family, 71(1), 174-186.

Xu, Y. (2001). Family support for old people in rural China. Social Policy \& Administration, 35(3), 307-320.

Yang, H, \& Chhandler, D. (1992). Intergenerational relations: grievances of the elderly in rural China. Journal of Comparative Family Studies, 23(3), 431-453.

Ye, Z. (2009). Establish a green cover for people - the 60-years of the social security program in China, People's Daily (overseas edition), Sept. 29, 2009.

Yin, Z.-X., Shi, X.-M., Kraus, V. B., Fitzgerald, S. M., Qian, H.-Z., Xu, J.-w., . . Zeng, Y. (2012). High normal plasma triglycerides are associated with preserved cognitive function in Chinese oldest-old. Age and ageing, 41(5), 600-606.

Zeng, Y., \& Gu, D (2008). Reliability of age reporting among the Chinese oldest-old in the CLHLS data sets. In Zeng Y., Poston, D. J, Vlosky, D.A, and Gu, D. (eds.). Healthy longevity in China: Demographic, socioeconomic, and psychological dimensions (pp. 6178). Dordrecht, The Netherlands: Springer Publisher. 
Zeng Y., George, L.K., Sereny, M., Gu, D. and Vaupel, J. W. (2015), Older parents enjoy better filial piety and care from daughters than sons in China -- The large survey denies the traditional son preference. Manuscript.

Zeng,Y., \& George L.K. (2010). Population Aging and Old-Age Care in China. In: Dale Dannefer and Chris Phillipson (eds.) Sage Handbook of Social Gerontology, Thousand Oaks/CA/USA: Sage Publications.

Zeng, Y. (2012). Towards Deeper Research and Better Policy for Healthy Aging--Using the Unique Data of Chinese Longitudinal Healthy Longevity Survey, China Economic Journal. Vol. 5, No. 2-3: 131.

Zhan, H. J. (2004). Willingness and expectations: Intergenerational differences in attitudes toward filial responsibility in China. Marriage \& Family Review, 36(1-2), 175-200.

Zhang, W. and Wang, Y. (2010). Meal and Residence Rotation of Elderly Parents in Contemporary Rural Northern China. Journal of Cross-Cultural Gerontology 25(3):217-237.

Zhu, H. (2015). Unmet needs in long-term care and their associated factors among the oldest old in China. BMC Geriatrics, 15:46. DOI 10.1186/s12877-015-0045-9.

Zunzunegui, M. V., Beland, F., \& Otero, A. (2001). Support from children, living arrangements, self-rated health and depressive symptoms of older people in Spain. International Journal of Epidemiology, 30(5), 1090. -149.

\footnotetext{
${ }^{1}$ A wide variety of international and Chinese studies (Coale \& Li, 1991; Wang et al., 1998; Poston \& Luo, 2004) have confirmed that the age reporting of Han Chinese oldest-old is acceptably accurate, but age reporting of minority ethnic groups in China is not accurate. The acceptably accurate age reporting of Han Chinese is due to their cultural tradition of memorizing their date of birth for determining important life events such as dates of engagement, marriage, starting to build a residential house, and even for long-distance traveling. These same practices are not carried out by ethnic minority groups. To ensure accurate age reporting among the sampled oldest-old interviewees, the CLHLS selected 22 Han-majority provinces as study areas and the other 9 provinces were excluded, due to the majority of the population being minority ethnic groups whose age reporting may not be accurate.

${ }^{2}$ The differences in the coefficients of adult daughters versus sons between urban and rural areas and between the young-old and oldest-old parents are statistically significant.
} 


\begin{tabular}{lccccc}
\hline Table 1. Descriptive Statistics & & & & & \\
\hline & Ages 65+ & Ages 65-79 & Ages 80+ & Urban & Rural \\
\hline $\begin{array}{l}\text { Sample size of cognitively unimpaired } \\
\text { elderly }\end{array}$ & $n=11,475$ & $n=6,354$ & $n=5,121$ & $n=5,136$ & $n=6,339$ \\
Total sample size & $n=19,697$ & $n=5,514$ & $n=14,183$ & $n=8,432$ & $n=11,265$ \\
Composition of living children (\%) & & & & & \\
$\quad$ No living children & 10.3 & 3.8 & 12.9 & 11.9 & 9.2 \\
$\quad$ Having 1+ daughter(s) only & 11.8 & 5.8 & 14.1 & $12 . .8$ & 11.0 \\
Having 1+ son(s) only & 14.6 & 12.3 & 15.4 & 14.0 & 15.0 \\
Having both son(s) and daughter(s) & 63.3 & 78.1 & 57.6 & 61.3 & 64.8 \\
\% of deceased respondents 2002-2008 & 55.9 & 19.6 & 70.0 & 54.8 & 56.8 \\
shares feelings with most frequently (\%) & & & & & \\
Spouse & 23.8 & 50.1 & 12.4 & 25.4 & 22.5 \\
Son and daughter-in-law & 36.1 & 21.8 & 42.3 & 29.3 & 41.8 \\
Daughter and son-in-law & 8.8 & 5.9 & 10.1 & 12.0 & 6.2 \\
Son and daughter & 6.2 & 5.8 & 6.5 & 7.2 & 5.4 \\
Other family member & 6.9 & 2.0 & 9.0 & 6.1 & 7.6 \\
Other & 10.91 & 9.5 & 11.5 & 12.8 & 9.3 \\
Control variables & & & & & \\
Mean Age & 86.6 & 72.0 & 92.7 & 86.5 & 86.5 \\
\% Han Ethnicity & 93.8 & 94.1 & 93.7 & 95.6 & 92.5 \\
\% currently married & 28.3 & 62.2 & 15.1 & 29.9 & 27.1 \\
\% Having 1+ years of schooling & 27.2 & 37.9 & 23.1 & 30.0 & 25.1 \\
\% with economic independence & 19.2 & 32.5 & 14.1 & 35.8 & 6.8 \\
Mean number of living children & 3.2 & 4.0 & 2.9 & 3.1 & 3.4 \\
\% Close proximity to children & 66.5 & 75.9 & 62.9 & 51.4 & 77.9 \\
\% Currently smokes & 18.5 & 28.4 & 14.6 & 16.7 & 19.8 \\
\% Currently drinks alcohol & 20.6 & 24.6 & 19.1 & 19.0 & 21.9 \\
\% Currently does regular exercise & 29.7 & 39.2 & 25.9 & 39.4 & 22.4 \\
Mean value of Deficit Index & 0.26 & 0.11 & 0.30 & 0.27 & 0.26 \\
\hline
\end{tabular}


Table 2. Odds Ratios of follow-up decline in cognitive capacity by with whom elderly parent shares feelings in daily life and gender composition of living adult children, based on data of 2002-2008 CLHLS

\begin{tabular}{lccccc}
\hline & $\begin{array}{c}\text { Ages 65+ } \\
(\mathrm{n}=11,475)\end{array}$ & $\begin{array}{c}\text { Ages 65-79 } \\
(\mathrm{n}=6,354)\end{array}$ & $\begin{array}{c}\text { Ages 80+ } \\
(\mathrm{n}=5,121)\end{array}$ & $\begin{array}{c}\text { Urban } \\
(\mathrm{n}=5,136)\end{array}$ & $\begin{array}{c}\text { Rural } \\
(\mathrm{n}=6,339)\end{array}$ \\
\hline $\begin{array}{l}\text { (A) Shares feelings most frequently } \\
\text { with daughter (and son-in-law) }\end{array}$ & $0.84^{*}$ & $0.67^{*}$ & 0.91 & 1.00 & $0.68^{*}$ \\
versus son (and daughter-in-law) & $(0.71,0.98)$ & $(0.47,0.94)$ & $(0.76,1.10)$ & $(0.80,1.25)$ & $(0.54,0.87)$ \\
$\begin{array}{l}\text { (B) Having daughter(s) only versus } \\
\text { having son(s) only }\end{array}$ & 0.86 & 0.80 & 0.89 & 0.89 & 0.84 \\
& $(0.70,1.06)$ & $(0.53,1.22)$ & $(0.70,1.13)$ & $(0.66,1.21)$ & $(0.64,1.12)$ \\
(C) Having daughter(s) only versus & 0.96 & 0.94 & 0.95 & 0.94 & 0.98 \\
having both son(s) and daughter(s) & $(0.80,1.15)$ & $(0.64,1.36)$ & $(0.77,1.17)$ & $(0.72,1.23)$ & $(0.76 .1 .26)$ \\
\hline
\end{tabular}

Notes: (1) All estimates are obtained from binary logistic regressions controlling for gender, single year of age, number of living children, proximity to children, urban/rural residence, ethnicity, education, economic status, marital status, and health practices (currently smoking, drinking alcohol and doing exercise). (2) $+p<0.1,{ }^{*} p<0.05,{ }^{* \star} p<0.01,{ }^{* \star *} p<0.001$. (3) Numbers in the parentheses are $95 \%$ confidence intervals. (4) The chi-square test results indicated that the model fits of the statistical models presented in this Table are significant.

Table 3. Relative mortality risks of elderly parents by with whom elderly parent shares feelings in daily life and gender composition of living adult children, based on data of 2002-2008 CLHLS

\begin{tabular}{|c|c|c|c|c|c|}
\hline & \multicolumn{2}{|c|}{ Both sex combined } & \multicolumn{3}{|c|}{ Rural and urban combined } \\
\hline & Rural & Urban & Males & Females & $\begin{array}{l}\text { Two } \\
\text { sexes }\end{array}$ \\
\hline I. All elderly parents aged 65+ & $\mathrm{n}=11,264$ & $\mathrm{n}=8,432$ & $\mathrm{n}=8,275$ & $\mathrm{n}=11,421$ & $\mathrm{n}=19,697$ \\
\hline $\begin{array}{l}\text { I-(A) Shares feelings most frequently with } \\
\text { daughter (and son-in-law) versus son } \\
\text { (and daughter-in-law) }\end{array}$ & $\begin{array}{c}0.87^{\star \star} \\
(0.79,0.95)\end{array}$ & $\begin{array}{c}0.99 \\
(0.91,1.07)\end{array}$ & $\begin{array}{c}0.92^{*} \\
(0.86,0.99)\end{array}$ & $\begin{array}{c}0.93 \\
(0.84,1.03)\end{array}$ & $\begin{array}{c}0.93^{\star} \\
(0.87,0.98)\end{array}$ \\
\hline $\begin{array}{l}\text { I-(B) Having daughter(s) only versus } \\
\text { having son(s) only }\end{array}$ & $\begin{array}{c}0.96 \\
(0.88,1.04)\end{array}$ & $\begin{array}{c}0.96 \\
(0.88,1.06)\end{array}$ & $\begin{array}{c}1.07 \\
(0.96,1.20)\end{array}$ & $\begin{array}{c}0.90^{\star \star} \\
(0.84,0.97)\end{array}$ & $\begin{array}{c}0.96 \\
(0.90,1.02)\end{array}$ \\
\hline $\begin{array}{l}\mathrm{I}-(\mathrm{C}) \text { Having daughter(s) only versus } \\
\text { having both son(s) and daughter(s) }\end{array}$ & $\begin{array}{c}0.98 \\
(0.92,1.10)\end{array}$ & $\begin{array}{c}0.99 \\
(0.91,1.07)\end{array}$ & $\begin{array}{c}1.03 \\
(0.94,1.12)\end{array}$ & $\begin{array}{c}0.97 \\
(0.91,1.03)\end{array}$ & $\begin{array}{c}0.98 \\
(0.93,1.04)\end{array}$ \\
\hline II. Young-old parents aged 65-79 & $n=3,233$ & $\mathrm{n}=2,281$ & $\mathrm{n}=2,834$ & $n=2,680$ & $n=5,514$ \\
\hline $\begin{array}{l}\text { II-(A) Shares feelings most frequently } \\
\text { with daughter (and son-in-law) versus } \\
\text { son (and daughter-in-law) }\end{array}$ & $\begin{array}{c}1.07 \\
(0.76,1.51)\end{array}$ & $\begin{array}{c}1.11 \\
(0.76,1.60\end{array}$ & $\begin{array}{c}1.25 \\
(0.86,1.82)\end{array}$ & $\begin{array}{c}1.02 \\
(0.74,1.41\end{array}$ & $\begin{array}{c}1.07 \\
(0.83,1.37)\end{array}$ \\
\hline $\begin{array}{l}\text { II-(B) Having daughter(s) only versus } \\
\text { having son(s) only }\end{array}$ & $\begin{array}{c}1.00 \\
(0.68,1.48)\end{array}$ & $\begin{array}{c}1.11 \\
(0.67,1.84) \\
\end{array}$ & $\begin{array}{c}1.01 \\
(0.68,1.52) \\
\end{array}$ & $\begin{array}{c}1.07 \\
(0.67,1.70)\end{array}$ & $\begin{array}{c}1.02 \\
(0.75,1.39) \\
\end{array}$ \\
\hline $\begin{array}{l}\text { II-(C) Having daughter(s) only versus } \\
\text { having both son(s) and daughter(s) }\end{array}$ & $\begin{array}{c}1.13 \\
(0.80,1.60)\end{array}$ & $\begin{array}{c}0.92 \\
(0.61,1.41)\end{array}$ & $\begin{array}{c}1.14 \\
(0.75,1.73)\end{array}$ & $\begin{array}{c}1.21 \\
(0.73,2.00)\end{array}$ & $\begin{array}{c}1.18 \\
(0.86,1.62)\end{array}$ \\
\hline III. Oldest-old parents aged $80+$ & $\mathrm{n}=8,031$ & $\mathrm{n}=6,151$ & $\mathrm{n}=5,441$ & $\mathrm{n}=8,741$ & $\mathrm{n}=14,182$ \\
\hline $\begin{array}{l}\text { III-(A) Shares feelings most frequently } \\
\text { with daughter (and son-in-law) versus } \\
\text { son (and daughter-in-law) }\end{array}$ & $\begin{array}{c}0.86^{\star *} \\
(0.78,0.94)\end{array}$ & $\begin{array}{c}0.98 \\
(0.90,1.06)\end{array}$ & $\begin{array}{c}0.91+ \\
(0.80,1.01)\end{array}$ & $\begin{array}{c}0.95 \\
(0.88,1.03)\end{array}$ & $\begin{array}{c}0.92^{\star *} \\
(0.87,0.98)\end{array}$ \\
\hline $\begin{array}{l}\text { III-(B) Having daughter(s) only versus } \\
\text { having son(s) only }\end{array}$ & $\begin{array}{c}0.95 \\
(0.88,1.03)\end{array}$ & $\begin{array}{c}0.94 \\
(0.85,1.04)\end{array}$ & $\begin{array}{c}1.06 \\
(0.95,1.18)\end{array}$ & $\begin{array}{c}0.90^{\star *} \\
(0.83,0.97)\end{array}$ & $\begin{array}{c}0.94+ \\
(0.89,1.01)\end{array}$ \\
\hline $\begin{array}{l}\text { III-(C) Having daughter(s) only versus } \\
\text { having both son(s) and daughter(s) }\end{array}$ & $\begin{array}{c}1.02 \\
(0.96,1.08) \\
\end{array}$ & $\begin{array}{c}0.99 \\
(0.91,1.07) \\
\end{array}$ & $\begin{array}{c}1.03 \\
(0.94,1.12) \\
\end{array}$ & $\begin{array}{c}0.95 \\
(0.89,1.02) \\
\end{array}$ & $\begin{array}{c}0.98 \\
(0.93,1.03)\end{array}$ \\
\hline
\end{tabular}

Notes: (1) All estimates are obtained from Weibull hazards survival analysis model controlling for gender, single year of age, number of living children, proximity to children, urban/rural residence, ethnicity, 
education, economic status, marital status, health practices (currently smoking, drinking alcohol and doing exercise), and deficit index at previous interviews. (2) $+p<0.1,{ }^{\star} p<0.05,{ }^{* \star} p<0.01,{ }^{* \star \star} p<0.001$; (3)

Figures in the parentheses are confidence intervals. (4) The chi-square test results indicated that the model fits of the statistical models presented in this Table are significant. 